\title{
Fluid Resuscitation and Massive Transfusion Protocol in Pediatric Trauma
}

\author{
Vesna Marjanović ${ }^{1}$, Ivana Budić 1,2 \\ ${ }^{1}$ Center for Anesthesiology and Reanimatology, Clinical Centre Niš, Serbia \\ ${ }^{2}$ University of Niš, Faculty of Medicine Niš, Serbia
}

\begin{abstract}
SUMMARY
Trauma is the leading cause of morbidity and mortality in children due to the occurrence of hemorrhagic shock. Hemorrhagic shock and its consequences, anemia and hypovolemia, decrease oxygen delivery, due to which appropriate transfusion and volume resuscitation are critical. Guidelines for massive transfusion, in the pediatric trauma, have not been defined yet. Current data indicate that early identification of coagulopathy and its treatment with RBSs, plasma and platelets in a 1:1:1 unit ratio, and limited use of crystalloids may improve survival in pediatric trauma patients.
\end{abstract}

Key words: fluid resuscitation, massive transfusion protocol, pediatric trauma 


\section{INTRODUCTION}

Trauma-related injuries are the leading cause of death in pediatric patients. Exsanguination, either at the site of the accident, or in hospital, accounts for $45 \%$ of all traumatic deaths. Motor vehicle collisions (59\% mortality from all accidents in age group 5-14), pedestrian and bicycle accidents, falls, burns, and physical assault are the most common causes of injury in children (1). Many of injured children will require surgical treatment with involvement of the anesthesiologist.

The major cause of morbidity and mortality in traumatized children is anemia and hypovolemia caused by hemorrhagic shock result in oxygen deprivation to vital organs. In order to improve decreased oxygen delivery, appropriate transfusion and volume resuscitation are critical. Although the fast infusion of fluids in trauma patient who is hemorrhagic and who has low pressure may seem undeniable, the end points for fluid administration to hemodynamically stable victims of blunt trauma and severe head injuries are unclear and not well established.

Also, in the pediatric population, there are no clear guidelines for massive transfusion. Adult trauma transfusion protocols can be utilized at children's age until a pediatric protocol is established (2). Here we tried to identify certain principles of fluid and transfusion therapies that are specific for pediatric trauma, and to present a sample of massive transfusion protocol (MTP) that can be used to guide resuscitation.

\section{EVALUATION OF VOLUME STATUS IN PEDIATRIC TRAUMA PATIENTS}

Hemorrhagic shock as a result of pediatric trauma is an uncommon but fundamental problem for the treating clinician, especially in cases of massive bleeding. Massive bleeding in children has been defined as the loss of one or more circulating blood volumes and all estimates of blood volume, volume loss and volume replacement are based on weight of children over the age of 3 months having an estimated blood volume of $70 \mathrm{ml} / \mathrm{kg}$, and younger infants having an estimated blood volume of $90 \mathrm{ml} / \mathrm{kg}$ (3).

The evaluation of the volume status of the pediatric trauma patients can be difficult since children are able to maintain a normal blood pressure in a supine condition with a loss of up to $20 \%$ of their blood volume. Physiologically, children have better hemodynamic compensation in the early stages of injury. Tachycardia is the first sign of hypovolemia in children, and it should not be overlooked, because children have small blood volumes, and delay in fluid resuscitation may rapidly lead to a significant decrease in hypovolemia (4). Other possible early signs of shock such as mental status change, respiratory compromise, absence of peripheral pulses, delayed capillary refill, skin pallor, and hypothermia must be immediately recognized. Having in mind that children have considerable cardiovascular reserve, the initial normal vital signs should not impart any sense of security with regard to the status of the child's circulating volume. Obvious signs of shock, such as hypotension (a late sign of hemorrhage in children) or a decrease in urinary output, may not occur until more than $30 \%$ of blood volume has been lost (5). Clinical monitoring should focus on perceived tissue oxygenation with continuous measurements of heart rate, pulse oximetry, arterial blood pressure. In massively bleeding patients, invasive monitoring can be extremely helpful in this population, and should never be omitted irrespective of the patient's age. Inserting the arterial line facilitates monitoring of blood pressure to a large degree, whereas central venous line provides valuable information about the cardiac filling pressures especially when the blood loss is such that cannot be quantified, for example in cases of internal bleeding or neurosurgical trauma. Experience from the literature suggests that 2-3 $\mathrm{mmHg}$ reduction in central venous pressure may reflect a loss of as much as $20 \%$ of the circulating blood volume (6).

Emergent procedures should not be postponed by waiting for the imaging and laboratory results. From all chest imaging methods, standard anteriorposterior chest X-ray is a cost-effective screening tool that will reveal most of the thoracic abnormalities (7). On the other hand, urinalysis or serum chemistries are of little use in pediatric trauma. From the specific testing, type and cross match blood, and hematocrit are indicated for a hemodynamiclly unstable patient. Serial hematocrits may help in the monitoring of solid organ injuries. Since coagulopathy is associated with trauma in general and with head injuries specifically, prothrombin time (PT), partial thromboplastin time (PTT), and international normalized ratio (INR) are useful tests in critically injured patients. Serial arterial blood gas testing is invaluable in assessing dynamic changes in hematocrit, oxygenation and acid-base status in critically ill children (8). What is the best 
level of haemoglobinat for pediatric trauma patients? Children are at least as capable as adults in their ability to compensate for lower hemoglobin concentrations with increased oxygen extraction and cardiac output, despite their limited myocardial compliance (9). Because of that, a specific level of blood loss or anemia that triggers RBC transfusion has not yet been defined in pediatric patients (3). A study done on hemodynamically stable, critically ill pediatric patients, the TRIPICU trial, showed no adverse effects when comparing a restrictive transfusion strategy initiated at a hemoglobin level of $7 \mathrm{~g} / \mathrm{dl}$ to a transfusion threshold of $9.5 \mathrm{~g} / \mathrm{dl}$ (10). A specific anemia threshold would be difficult to use as a trigger for MTP activation in the case of massive hemorrhage, because hemoglobin and hematocrit levels might not reveal significant anemia until the patient had been volume resuscitated, making a precise estimate of lost blood volume difficult to ascertain based on these laboratory tests $(3,11)$.

Children with hemorrhagic shock have a physiological predictors of adverse outcome, as a high Injury Severity Score (ISS), shock and high base deficit on admission, which are independent predictors of increased mortality in the general pediatric trauma population. Patregnani et al. (12) found that coagulopathy (INR $\geq 1,5$ ) on admission was common and associated with increased mortality in children with traumatic injuries, independent of the ISS Vavilala et al. (13) found that the presence of coagulopathy (defined by increased fibrin degradation products) independently predicted poor outcome in children with isolated head injury. Several mechanisms have been proposed to explain the coagulation abnormalities associated with TBI, which show a combination of both hypocoagulable and hypercoagulable states (14). It has also been hypothesized that the trauma causes local release of tissue factor from the injured neurons, which is associated with activation of the protein $C$ pathway, thus triggering the release of anticoagulant mediators (15). Borgman et al. (16) found both admission base deficit $<8$ and INR $>1.8$ to be independently associated with mortality, and proposed that a score based on these predictors of adverse outcome („BIG" score: base deficit + [2.5 x INR] + [15- GCS score]) may more accurately predict mortality in pediatric trauma patients than scoring systems currently in use. Measurements of admission base deficit are frequently used as markers of tissue hypoperfusion and shock. The prognostic value of lactate levels has not yet been defined in pediatric patients. Several investigators suggest using shock index (defined as heart rate/systolic blood pressure) as an indicator of tissue perfusion as it reflects both vascular and myocardial dysfunction (17).

\section{FLUID RESUSCITATION IN CHILDREN}

After the initial evaluation of patients with pediatric trauma, it is important to prevent hypothermia. Hypotermia results in vasoconstriction, low-flow state, acidosis, and consumptive coagulopathy. The use of warm intravenous fluids and covering the patient with warm blanket may prevent hypothermia. Connective air rewarmers (e.g. Bear Hugger) and warmed, humidified ventilation can help maintain core body temperature, if hypothermia is detected $\left(<35^{\circ} \mathrm{C}\right)$. Peritoneal lavage with warm saline may assist with hypothermia refractory to prior measures (18).

Control of bleeding and fluid resuscitation on an injured child remains to be a crucial step in trauma care. Early intravenous access with appropriate fluid administration continues to be a universal treatment for hypotensive trauma patient. Up-to-date management of hemorrhagic shock still involves the initial resuscitation with crystalloid fluids followed by an infusion of blood components as necessary. Initial fluid resuscitation should begin with the warm isotonic crystalloid solution (Ringer's lactate or isotonic sodium chloride solution) at a bolus of $20 \mathrm{ml} / \mathrm{kg}$. The goal of initial resuscitation should be to achieve hemodynamic stability and to restore adequate tissue perfusion as soon as possible. The end-points of fluid resuscitation in children usually include normalization of pulse rate and urine output $>1$ $\mathrm{ml} / \mathrm{kg} / \mathrm{h}$. Recent literature has questioned the timing, type, and amount of fluid administration during the resuscitative phase. Some authors found insufficient evidence for or against the use of early or larger volume fluid resuscitation in the treatment of uncontrolled hemorrhage. While vigorous fluid resuscitation may be life-saving in some patients, results from clinical trials are inconclusive. In bleeding trauma patients, the liberal use of isotonic crystalloids to correct hypotension was recommended by the Advanced Trauma Life Support (ATLS) protocol of the American College of Surgeons. Nevertheless, they could find no reliable evidence to support or not to support this recommendation. The authors of the recommendation deny the possibility of overlooking a large high-quality randomized controlled 
trial, showing that early or larger volume fluid resuscitation is beneficial (19).

The adverse effects of hemodilution in children were described by Hussmann et al. (20), who found that increased prehospital crystalloid volume replacement was associated with increased transfusion requirements, adversely affected coagulation (defined by a prolonged PT) and a tendency towards increased mortality and multiple organ failure (MOF) rates. A comprehensive standard protocol cannot be established for these situations. Prehospital volume replacement in the most severely injured children is associated with a number of perils and should be critically estimated, except in the case of absolute indications, e.g. traumatic brain injury. Excessive prehospital volume replacement (overresuscitation) with crystalloids in injured children can have a negative effect on the clinical course (e.g. a higher rate of MOF and mortality). The decision to start with the increased volume replacement therapy at the accident site must be made on a case-by-case basis (20).

Hypertonic saline was shown to increase hemodynamic stability and decrease fluid requirements in adult trauma patients, but it did not affect the survival rate $(21,22)$. One might consider the use of hypertonic saline when trauma is associated with a closed head injury (23). However, more evidence for the use of hypertonic saline in children is needed. Hydroxyethil starch and albumin have also been used in children with insignificant adverse effects $(24,25)$. Hemodilution with large amounts of colloids may have negative effects on hemosthasis. Comparing the effects of hydroxyethyl starch (HES) and human albumin (HA) on coagulation by thrombelastography in children weighing $3-15 \mathrm{~kg}$ (26), Haas et al. (27) found more impaired coagulation after the use of HES. Volume replacement with HA may be associated with higher mortality rate in trauma patients with TBI when compared to saline (27). Caution is therefore warranted, and colloids should not be used for replacement of volume in the trauma patients, given the high rate of early coagulopathy and TBI in the children $(28,29)$.

In children with head injury, dextrose-containing fluids should not be given because hypotonic solutions may lead to the development of cerebral edema (30). In case of hyperglycemia, children with a head injury have a higher risk to develop poor neurological outcome. However, hypoglycemia is also harmful for a suffering brain, and should be avoided (31).

\section{PEDIATRIC MASSIVE TRANSFUSION PROTOCOL}

Children with evidence of hemorrhagic shock who fail to response to fluid resuscitation should also receive blood and be evaluated by a pediatric surgeon for possible operative intervention. Guidelines regarding transition from clear fluids to blood and blood products are not well-established in pediatric trauma. Clinical decision either follows adult protocols, or is made per individual clinical judgment (32).

Besides containing fibrinogen, which is essential for clot formation, FFP is an excellent volume expander. So is $\mathrm{RBC}$, and patients that require massive transfusion should therefore be given RBC and FFP as volume therapy to treat their hypovolemia causing hypoperfusion with ensuing oxygen debt and coagulation factor depletion, rather than crystalloids (33). Studies in adult populations have shown that an increased ratio of PLT and FFP to RBC show an association with improved survival in massively bleeding trauma and non-trauma patients $(33,34)$. Nosanov et al. (35) did not find the same association between increased FFP or PLT to RBC ratios and decreased mortality in massively transfused pediatric trauma patients. This group defined massive transfusion as more than $50 \%$ of total blood volume lost within 24 hours. The use of warm fresh whole blood for adult patients with traumatic injuries has shown to be independently associated with higher rate of survival for 30 days (36). Some authors found that there was significantly less postoperative blood loss in the group of 161 children undergoing open heart surgery, receiving fresh whole blood, and ascribed this to better functioning platelets (37). Based on these data, whole blood could potentially be used as an alternative to reconstituted whole blood in trauma settings for hemostatic resuscitation in centers that are able to handle and store it correctly. More investigation into the utility of whole blood in the emergency setting for pediatric resuscitation is warranted. Dressler et al. (38) described the use of a MTP in the case of a child with severe intraoperative bleeding ( $>4$ liters ). They applied a blood product ratio of 4:4:5 units of RBC:FFP:PLT perioperatively, and did not find the signs of coagulopathy postoperatively. Pickett et al. (39) described the use of MTP consisting of 6:3:5 ratio of RBC:FFP:PLT for pre- and perioperative transfusion in a 
15-year old boy with an estimated blood loss of 10 liters due to a gunshot wound to the chest. The patient did not present with or develop coagulopathy after resuscitation. Paterson et al. (40) presented the child with severe intracranial bleeding caused by an arterio-venous malformation, resulting in an estimated loss of more than 5-6 blood volumes. Their MTP, after the loss of 2 blood volumes with expected continued bleeding, consisted of RBC, FFP and PLT given in a ratio of $30: 20: 20 \mathrm{ml} / \mathrm{kg}$ (total $70 \mathrm{ml} / \mathrm{kg}$ ) in each cycle. The patient survived and was admitted to the ICU with a normal postoperative coagulation profile.

In most institutions that are not only children's hospitals, pediatric massive transfusion protocols would need to reflect or complement adult MTPs. The logistics of blood bank operations and the need for straightforward, unambiguous protocols in the trauma bay would likely demand that existing adult MT protocols, which are centered mostly on a PRBC/FFP/PLT ratio of 1:1:1, be followed for most pediatric patients as well. However, these protocols should not be used for small children $(<30 \mathrm{~kg})$, for whom transfusions must be given based on their weight. A starting point for a pediatric MT protocol would include the following elements:

1. Initiation of MT protocol in traumatic hemorrhagic shock with persistent hemodynamic instability or ongoing bleeding after $40 \mathrm{ml} / \mathrm{kg}$ of crystalloid infusion

2. Blood components delivered to larger pediatric patients $(>30 \mathrm{~kg})$ at a ratio of 1:1:1 units of PRBC/FFP/PLT with cryoprecipitate given for low fibrinogen levels $(<1-1.5 \mathrm{~g} / \mathrm{l})$ or during bleeding after the administration of 1 round of all 3 blood components. For pediatric trauma patients less than $30 \mathrm{~kg}$, a weight-based protocol at a ratio of 30: 20:20 would be initiated (40).

3. Appropriate maintenance of body temperature, serum calcium, and blood $\mathrm{pH}$.

4. Consideration of use of rFVIIa in extreme cases. Doses between 20 and $180 \mu \mathrm{g} / \mathrm{kg}$ have been given in adults and pediatric patients, although it is important not to forget that use in trauma situations is off-label (3).

5. In the future, the use of hemoglobin substitutes is confirmed in adult patients with additional experience. These products along with other plasma expanders may have a role in pediatric trauma algorithm.

\section{CONCLUSIONS}

Management of pediatric patients with trauma requires the knowledge of the special considerations and understanding of the pathophysiology and special requirements of the pediatric population. Current data indicate that early identification of coagulopathy and its treatment with RBC, FFP, and PLT in a 1:1:1 unit ratio achieved with the use of fresh RBCs, thawed plasma, and platelets, limited use of crystalloids, careful consideration of resuscitation adjuncts, such as rFVIIa, may improve survival in uncommon pediatric trauma patients, who presents with severe traumatic injury and life-threatening bleeding. In the future, dedicated multicenter research will be needed to evaluate outcomes associated with implementation of MT protocols in pediatric trauma patients. 


\section{References}

1. Heron M, Hoyert DL, Murphy SL et al. Deaths: Final data for 2006. Natl Vital Stat Rep 2009; 57: $1-134$.

2. Hess JR, Bronhi K, Dutton RP et al. The coagulopathy of trauma: a review of mechanisms. J Trauma 2008; 65: 748-54. http://dx.doi.org/10.1097/TA.0b013e3181877a9c

3. Dehmer JJ, Adamson WT. Massive transfusion and blood product use in the pediatric trauma patient. SeminPediatrSurg 2010; 19: 286-91. http://dx.doi.org/10.1053/j.sempedsurg.2010.07.002

4. Bernardo LM, Gardner MJ, Lucke J et al. The effects of core and peripheral warming methods on temperature and physiologic variables in injured children. PediatrEmerg Care 2001; 17: $138-42$.

http://dx.doi.org/10.1097/00006565-20010400000016

5. Cassey JG, Armstrong PJ, Smith GE et al. The safety and effectiveness of a modified convection heating system for children during anesthesia. PaediatrAnaesth 2006; 16: 654-62. http://dx.doi.org/10.1111/j.1460-9592.2006.01848.x

6. Pinsky MR. Probing the limits of arterial pulse contour analysis to predict preload responsiveness. AnesthAnalg 2003; 96: 1245-7. http://dx.doi.org/10.1213/01.ANE.0000055821.400 75.38

7. Renton J, Kincaid S, Ehrlich PF. Should helical CT scanning of the thoracic cavity replace the conventional chest $\mathrm{x}$-ray as a primary assessment tool in pediatric trauma? An efficacy and cost analysis. J PediatrSurg 2003; 38: 793-7. http://dx.doi.org/10.1016/jpsu.2003.50169

8. Linzer J. Do routine laboratory tests add to the care of the pediatric trauma patient? ClinPediatrEmerg Med 2010; 11: 4. http://dx.doi.org/10.1016/j.cpem.2009.12.006
9. Istaphanous GK, Wheeler DS, Lisco SJ et al. Red blood cell transfusion in critically ill children: a narrative review. PediatrCrit Care Med 2011; 12(2): 174-83.

http://dx.doi.org/10.1097/PCC.0b013e3181e30d09

10. Lacroix J, Hebert PC, Hutchison JS et al. Transfusion strategies for patients in pediatric intensive care units. N Engl J Med 2007; 356(16): 1609-19. http://dx.doi.org/10.1056/NEJMoa066240

11. Barcelona SL, Thompson AA, Cote CJ. Intraoperative pediatric blood transfusion therapy: a review a common issues. Part II: transfusion therapy, special considerations, and reduction of allogenic blood transfusions. PaediatrAnaesth 2005; 15(10): 814-30. http://dx.doi.org/10.1111/j.1460-9592.2004.01549.x

12. Patregnani JT, Borgman MA, Maegele $\mathrm{M}$ et al. Coagulopathy and shock on admission in associated with mortality for children with traumatic injuries at combat support hospitals. PediatrCrit Care Med 2012; 13(3): 273-7. http://dx.doi.org/10.1097/PCC.0b013e31822f1727

13. Vavilala MS, Dunbar PJ, Rivara FP et al. Coagulopathy predicts poor outcome following head injury in children less than 16 years of age. J NeurosurgAnesthesiol 2001; 13(1): 13-8. http://dx.doi.org/10.1097/00008506-20010100000003

14. Harhangi BS, Kompanje EJ, Leebeek FW et al. Coagulation disorders after traumatic brain injury. ActaNeurochir 2008; 150(2): 165-75.

http://dx.doi.org/10.1007/s00701-007-1475-8

15. Cohen MJ, Call M, Nelson M et al. Critical role of activated protein $\mathrm{C}$ in early coagulopathy and later organ failure, infection and death in trauma patients. Ann Surg 2012; 255(2): 379-85. http://dx.doi.org/10.1097/SLA.0b013e318235d9e6 
16. Borgman MA, Maegele M, Wade CE et al. Pediatric trauma BIG score: predicting mortality in children after military and civilian trauma. Pediatrics 2011; 127(4): e892-7. http://dx.doi.org/10.1542/peds.2010-2439

17. Birkhahn RH, Gaeta TJ, Terry D et al. Shock index in diagnosing early acute hypovolemia. Am J Emerg Med 2005; 23: 323-6. http://dx.doi.org/10.1016/j.ajem.2005.02.029

18. Varon AJ, Smith CE, editors. Essentials of trauma anesthesia. Cambridge: Cambridge University Press; 2012.

http://dx.doi.org/10.1017/CBO9781139061339

19. Kwan I, Bunn F, Chinnock P et al. Timing and volume of fluid administration for patients with bleeding. Cochrane Database Syst Rev 2014; 3: CD002245.

http://dx.doi.org/10.1002/14651858.cd002245.pub2

20. Hussmann B, Lefering R, Kauther MD et al. Influence of prehospital volume replacement on outcome in polytraumatized children. Crit Care 2012; 16(5): R201.

http://dx.doi.org/10.1186/cc11809

21. Younes RN, Aun F, Accioly CQ et al. Hypertonic solutions in the treatment of hypovolemic shock: A prospective, randomized study in patients admitted to the emergency room. Surgery 1992; 111: 380-5.

22. Bulger EM, May S, Kerby JD et al. Out-ofhospital hypertonic resuscitation after traumatic hypovolemic shock: A randomized, placebo controlled trial. Ann Surg 2011; 253: 431-41. http://dx.doi.org/10.1097/SLA.0b013e3181fcdb22

23. Morrow SE, Pearson M. Management strategies for severe closed head injuries in children. SeminPediatrSurg 2010; 19: 279-85. http://dx.doi.org/10.1053/j.sempedsurg.2010.07.001

24. Doyle JA, Davis DP, Hoyt DB. The use of hypertonic saline in the treatment of traumatic brain injury. J Trauma 2001; 50: 367-83. http://dx.doi.org/10.1097/00005373-200102000-00030

25. Sumpelmann R, Kretz FJ, Gabler $\mathrm{R}$ et al. Hydroxyethyl starch 130/0.42/6:1 for perioperative plasma volume replacement in children: preliminary results of a European Prospective Multicenter Observational
Postauthorization Safety Study (PASS). PaediatrAnaesth 2008; 18: 929-33.

http://dx.doi.org/10.1111/j.1460-9592.2008.02696.x

26. Standl T, Lochbuehler $\mathrm{H}$, Galli $\mathrm{C}$ et al. HES 130/0.4 (Voluven) or human albumin in children younger than $2 \mathrm{yr}$ undergoing non-cardiac surgery. A prospective, randomized, open label, multicentre trial. Eur J Anaesthesiol 2008; 25: 437-45. http://dx.doi.org/10.1017/S0265021508003888

27. Haas T, Mauch J, Weiss M et al. Management of Dilutional Coagulopathy during Pediatric Major Surgery. Transfus Med Hemother 2012; 39(2): 114-9. http://dx.doi.org/10.1159/000337245

28. Myburgh J, Cooper DJ, Finfer S et al. Saline or albumin for fluid resuscitation in patients with traumatic brain injury. N Engl J Med 2007; 357(9): 874-84.

http://dx.doi.org/10.1056/NEJMoa067514

29. Kaieda R, Todd MM, Cook LN et al. Acute effects of changing plasma osmolality and colloid oncotic pressure on the formation of brain edema after cryogenic injury. Neurosurgery 1998; 24: 671-8.

http://dx.doi.org/10.1227/00006123-19890500000003

30. Cochran A, Scaife ER, Hansen KW et al. Hyperglicemia and outcome from pediatric traumatic brain injury. J Trauma 2003; 55: 1035-8. http://dx.doi.org/10.1097/01.TA.0000031175.96507.48

31. Udani V, Munot P, Ursekar M et al. Neonatal hypoglycemic brain - injury a common cause of infantile onset remote symptomatic epilepsy. Indian Pediatr 2009; 46: 127-32.

32. Rossaint R, Bouillon B, Cerny V et al. Management of bleeding following major trauma: An updated European guideline. Crit Care 2010; 14: R52. http://dx.doi.org/10.1186/cc8943

33. Holcomb JB, Wade CE, Michalek JE et al. Increased plasma and platelet to red blood cell rations improves outcome in 446 massively transfused civilian trauma patients. Ann Surg 2008; 248(3): 447-58.

34. Del Junco DJ, Holcomb JB, Fox EE et al. Resuscitate early with plasma and platelets or 
balance blood products gradually: findings from the PROMMTT study. J Trauma Acute Care Surg 2013; 75(1 Suppl 1): S24-30.

http://dx.doi.org/10.1097/TA.0b013e31828fa3b9

35. Nosanov L, Inaba K, Okoye O et al. The impact of blood products rations in massively transfused pediatric trauma patients. Am J Surg 2013; 206(5): 655-60.

http://dx.doi.org/10.1016/j.amjsurg.2013.07.009

36. Spinella PC, Borgman MA, Azarow KS. Pediatric trauma in an austere combat environment. Crit Care Med 2008; 36(7 Suppl): S293-6.

http://dx.doi.org/10.1097/CCM.0b013e31817da99f

37. Manno CS, Hedberg KW, Kim HC et al. Comparison of the hemostatic effects of fresh whole blood, stored whole blood, and components after open heart surgery in children. Blood 1991; 77(5): 930-6.

38. Dressler AM, Finck CM, Caroll CL et al. Use of a massive transfusion protocol with hemostatic resuscitation for severe intraoperative bleeding in a child. J Ped Surg 2010; 45(7): 1530-3.

http://dx.doi.org/10.1016/j.jpedsurg.2010.03.023

39. Pickett PM Tripi PA. Masive transfusion protocol in pediatric trauma. Int Anesthesiol Clin 2011; 49(2): 62-7.

http://dx.doi.org/10.1097/AIA.0b013e3181f955d8

40. Paterson NA. Validation of the theoretically derived model for the management of massive blood loss in pediatric patients-a case report. Pediatr Anaesth 2009; 19(5): 535-40. http://dx.doi.org/10.1111/j.1460-9592.2009.02982.x 


\title{
Nadoknada tečnosti i protokol masovne transfuzije kod traumatizirane dece
}

\author{
Vesna Marjanović ${ }^{1}$, Ivana Budić 1,2 \\ ${ }^{1}$ Centar za anesteziologiju i reanimatologiju, Klinički centar Niš, Niš, Srbija \\ ${ }^{2}$ Univerzitet u Nišu, Medicinski fakultet, Niš, Srbija
}

\section{SAŽETAK}

Trauma je vodeći uzrok morbiditeta i mortaliteta kod dece usled nastanka hemoragičnog šoka. Hemoragični šok i njegove posledice, poput anemije i hipovolemije, smanjuju isporuku kiseonika tkivima, zbog čega primena derivata krvi $i$ nadoknada tečnosti mogu biti od vitalne važnosti. U pedijatrijskoj populaciji, indikacije za primenu masivne transfuzije krvi su još uvek nejasne. Trenutni podaci ukazuju da je rana identifikacija koagulopatije i lečenje ovakvih bolesnika eritrocitima, plazmom i trombocitima $u$ odnosu 1:1:1, ograničeno korišćenje kristaloida, može poboljšati preživljavanje traumatizirane dece.

Ključne reči: nadoknada tečnosti, protokol masivne transfuzije, trauma kod dece 